This is an electronic reprint of the original article. This reprint may differ from the original in pagination and typographic detail.

Author(s): Hernoux-Villière, Audrey; Lévêque, Jean-Marc; Kärkkäinen, Johanna; Papaiconomou, Nicolas; Lajunen, Marja; Lassia, Ulla

Title: $\quad$ Task-specific ionic liquid for the depolymerisation of starch-based industrial waste into high reducing sugars

Year: $\quad 2014$

Version:

Please cite the original version:

Hernoux-Villière, A., Lévêque, J.-M., Kärkkäinen, J., Papaiconomou, N., Lajunen, M., \& Lassia, U. (2014). Task-specific ionic liquid for the depolymerisation of starch-based industrial waste into high reducing sugars. Catalysis Today, 223(March), 11-17. https://doi.org/10.1016/j.cattod.2013.09.027

All material supplied via JYX is protected by copyright and other intellectual property rights, and duplication or sale of all or part of any of the repository collections is not permitted, except that material may be duplicated by you for your research use or educational purposes in electronic or print form. You must obtain permission for any other use. Electronic or print copies may not be offered, whether for sale or otherwise to anyone who is not an authorised user. 


\title{
Task-specific ionic liquid for the depolymerisation of starch-based industrial waste into high reducing sugars
}

Audrey Hernoux-Villière ${ }^{1,2}$, Jean-Marc Lévêque ${ }^{2}$, Johanna Kärkkäinen ${ }^{3}$, Nicolas Papaiconomou ${ }^{2}$, Marja Lajunen $^{3} \&$ Ulla Lassi ${ }^{1,3}$

\footnotetext{
${ }^{1}$ Kokkola University Consortium Chydenius, Talonpojankatu 2B, 67100 Kokkola, Finland;

${ }^{2}$ Laboratoire de Chimie Moléculaire et Environnement, Université de Savoie, 73376 Le Bourget du Lac Cedex, France

${ }^{3}$ University of Oulu, Department of Chemistry, P.O. Box 3000, FI-90014 Oulu, Finland
}

\begin{abstract}
Development of a simple route for the catalytic conversion of starch-based industrial waste (potato peels) and potato starch into reducing sugars was investigated in two ionic liquids for comparison - 1-allyl-3methylimidazolium chloride [AMIM]Cl and 1-(4-sulfobutyl)-3-methylimidazolium chloride [SBMIM]Cl. Over a two hour period, a $20 \mathrm{wt} \%$ solution containing up to $43 \%$ and $98 \%$ of reducing sugars at low temperature in aqueous [SBMIM]Cl were achieved for the starch-based waste and the potato starch, respectively. In addition, the use of microwave and low frequency ultrasound to perform the depolymerisation of the raw starch-based material was explored and compared with conventional heating processes.
\end{abstract}

\section{Introduction}

A growing concern in environmental sustainability in our society has become an important aspect for both ecosystem health and economic development. The intensive consumption of fossil fuels that will eventually run out renders renewable resources as an attractive proposition. Some by-products can be considered as sustainable energy for the synthesis of chemicals [1]. Currently, a Finnish company, which produces pre-cooked vacuum potatoes, generates several tons of waste from potato peels daily. In our previous study [2], a weight percentage of sugars was performed on by a total hydrolysis of the by-product, which is mainly composed of glucose 
$(80.2 \%)$, mannose $(4.9 \%)$ and galactose $(3.2 \%)$. More than $88 \%$ can be subsequently considered as the total sugar potential. This by-product is mainly composed of starch, the principal constituent of potatoes. Starch is basely composed of two macromolecules, amylose and amylopectin, trapped into granules. Its depolymerisation into reducing sugars is mainly performed under concentrated strong acidic conditions and/or high temperature, for long reaction time [3], [4]. However, starch molecules are not prone to accept water dissolution, notably due to the strong intra and intermolecular hydrogen bonds. These latters can be generally broken down under high temperature, shear and acidic conditions, yielding both free macromolecules [5]. The depolymerisation process in a water medium is therefore of a heterogeneous nature and suffers some inevitable limitations (existence of diffusion layers, limitation of the mass transfer, lack of efficient mixing, etc.) whereas homogeneous media will certainly bring a higher reactivity [6], [7]. One possibility for the dissolution of starch is to use ionic liquids [8]. Known as salt with a melting point below $100^{\circ} \mathrm{C}$, ionic liquids possess attracted properties as new generation of solvents, negligible vapour pressure, wide liquid ranges (up to $400{ }^{\circ} \mathrm{C}$ ) and the ability to dissolve carbohydrate [9]. Dissolution of carbohydrates up to $20-\mathrm{wt} \%$ in ionic liquids has been reported previously [10]. In 2006, Remsing et al. investigated the solvation of cellulose in an imidazolium-based ionic liquid bearing a chloride counter-anion [11]. Due to their high nucleophilic capacity, chloride ions are enabled to interact with the hydroxyl protons of carbohydrates and to break down the hydrogen-bonding network to promote dissolution. In our experiments, the first selected ionic liquid was 1-allyl-3-methylimidazolium chloride [AMIM]Cl, which has an excellent ability to dissolve carbohydrates [12] and depolymerise them in the presence of solid catalysts [13] or acid [14]. Brønsted acidic ionic liquids (BAILs) possess simultaneously a proton acidity with the Brønsted function and properties of ionic liquids - non-volatile, recyclable [7], [15], [16]. A wide range of moieties can be classified in the Brønsted framework: mineral acids, sulfonates, phosphonates, and carboxylic acids. Johnson et al. [17] published a detailed review about fundamentals of BAILs and their use in various organic reactions with different location of the Brønsted acid function (anion or/and cation). The strength of the acidity depends on the position of the acidic function; $-\mathrm{COOH}$ or $-\mathrm{SO}_{3} \mathrm{H}$ function on cation possess strong intrinsic acidity [17]. $\mathrm{SO}_{3} \mathrm{H}-$ functionalised ionic liquids are strong Brønsted acids [6], [15], [18] and possess great potential as dual catalyst/solvent system and non-volatile acidic materials [19]. 1-(4-sulfobutyl)-3-methylimidazolium chloride [SBMIM]Cl possesses Brønsted-acidic sulfonic group on the cation to play the role of both solvent and catalyst. The chloride anion was preserved to enable the primary target, i.e. the solubilisation of the solute [20].

Both ionic liquids (see Fig. 1 for structures and abbreviations) are already well known in literature as they have been previously employed mainly for the dissolution and hydrolysis of cellulose into reducing sugars [7], [21], 
[22], [23], and to the best of our knowledge, no studies have been performed on native potato starch and particularly on a real industrial waste material.

The main goal of this research was therefore to dissolve and to depolymerise natural starch-based raw materials into reducing sugars in ionic liquids. To overcome the viscosity of these ionic liquids, we decided to explore the effect of low frequency ultrasound and microwave irradiation. Whereas the rapid heating of microwave irradiation can decrease the viscosity and thus enhance mass transfer, low frequency ultrasound, through their strong mechanical effects (harsh mixing, local heating, mass transfer, etc.) may help to stir in an efficient way the ionic liquids phase [24], [25].

\section{Materials and methods}

\subsection{Materials and preparation of ionic liquids}

Three different raw materials were utilised for comparison: potato starch, wet potato sludge and dry potato sludge. Potato starch was purchased at a local supermarket, composed solely of starch extracted from potatoes and utilised as the reference. Wet potato sludge is an industrial by-product composed of waste potato peels. Half centimetre of potato containing peels was roughly removed with a potato rotating peeler machine. The third raw material used is dry potato sludge, which is wet potato sludge dried under a vacuum line and ground with a mortar and pestle prior to use. Loss on drying analyses [2] were performed on potato starch, wet potato sludge and dry potato sludge revealing 10, 67 and $10 \%$, respectively. These results were confirmed by a thermogravimetric analysis performed in a previous study [26].

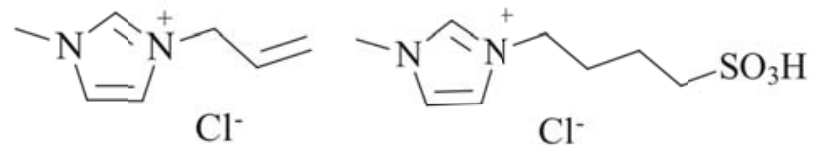

(A)

(B)

Fig. 1. (A) 1-Allyl-3-methylimidazolium chloride [AMIM]Cl and (B) 1-(4- sulfobutyl)-3-methylimidazolium chloride (Brønsted-acidic ionic liquid) [SBMIM]Cl.

1-Methylimidazole, allylchloride, 1,4-butane sultone and solvents were purchased from VWR Finland and Sigma-Aldrich France whilst hydrochloric acid 37\% (Baker analysed ACS Reagent ${ }^{\circledR}$, VWR Finland) was commercially available. The ionic liquid [AMIM]Cl was synthesised according to the procedure published by Hao Zhang et al. [27] with minor modifications. A typical procedure is as follows: in an adapted round-bottom 
flask flushed with argon (10 min), allylchloride $(50 \mathrm{~mL}, 610 \mathrm{mmol})$ was added dropwise over 1-methylimidazole placed into a water/ice bath (due to exothermic reaction) to achieve 1:1.25 proportions. Afterwards, the solution was stirred for 18 hours at $55^{\circ} \mathrm{C}$. The ionic liquid was washed several times with ethyl acetate $(3 \times 40 \mathrm{~mL})$ and cyclohexane $(3 \times 40 \mathrm{~mL})$. In order to obtain a clean ionic liquid, activated charcoal and methanol (Gradient Grade $-50 \mathrm{~mL}$ ) were stirred with the ionic liquid for $90 \mathrm{~min}$ and then filtered on Celite ${ }^{\circledR}$ [28]. The ionic liquid was then dried under a vacuum line and a water-content of $0.1 \mathrm{wt} \%$ was measured by Karl Fisher coulometric titration (Metrohm 831KF coulometer) using Hydranal 34843 Coulomat AG-H (Fluka) as titrant. The synthesis of the [SBMIM]Cl was also based on literature [29] with minor modifications; the detailed protocol was as follow: 1,4-butane sultone $(200 \mathrm{mmol})$ was added dropwise to 1 -methylimidazole whilst being stirred in a 250 $\mathrm{mL}$ round-bottom flask, flushed with argon for $10 \mathrm{~min}$ beforehand. The solution was then heated to $70{ }^{\circ} \mathrm{C}$ for 1 hour and the resulting solid was then cooled down, crushed and washed several times with toluene and cyclohexane. The zwitterion obtained was dried in a vacuum oven for 12 hours (yield $>98 \%$ ) followed by adding droplets of hydrochloric acid $37 \%$ to the zwitterion in stoichiometric proportions. The solution was stirred and heated at $70{ }^{\circ} \mathrm{C}$ for 2 hours. The resulting mixture was washed with toluene $(3 \times 20 \mathrm{~mL})$ and cyclohexane $(3 \times 20 \mathrm{~mL})$ before being cleaned with activated charcoal in methanol (Gradient Grade $-30 \mathrm{~mL})$ to obtain a clear solution. Ionic liquids are clear compounds, and a more or less yellowish result from traces of compounds originating from the reagents [30]. The solvents were then evaporated with a rotary evaporator and a yellowish ionic liquid was formed in the inner layer of the pear-bottom flask. The ionic liquid was dried again in a vacuum oven for 12 hours at $70{ }^{\circ} \mathrm{C}$. NMR and FTIR were performed on both ionic liquids (see section 2.3) whilst a low frequency $(24 \mathrm{kHz})$ ultrasound bath (Kerry Pulsatron) and a Prolabo Synthewave S402 (electric power $600 \mathrm{~W}$ ) microwave were employed for depolymerisation.

\subsection{Dissolution and depolymerisation methods}

A 10 or $20 \mathrm{wt} \%$ solution of starch in an ionic liquid medium was stirred or irradiated for 120 min at several temperatures $\left(60\right.$ to $\left.90{ }^{\circ} \mathrm{C}\right)$. The three previously stated materials were then added to the heated solution to ease dissolution. A conical vial of $5 \mathrm{~mL}$ with a dedicated triangle magnet was employed for the mechanical stirring reactions. A $10 \mathrm{~mL}$ round-bottom flask and a $20 \mathrm{~mL}$ tube flask were used for the ultrasound and microwave irradiations respectively. For the former, the indirect mode of irradiation, i.e use of an ultrasonic bath, is justified by the acidity of the selected TSIL whereas, the direct mode of irradiation would suggest the use of an ultrasonic 
probe directly immersed in the solution. This would exposure the probe to corrosion and other damages. To prevent this, an ultrasonic bath filled with water was selected in which the reactor is immersed. A minimum of $10 \%(w / w)$ of distilled water was added to the reaction with [SBMIM]Cl in order to dissociate the sulfonic acid function. Afterwards, the sample was dissolved into $10 \mathrm{~mL}$ of distilled water and neutralised with crushed pellets of sodium hydroxide. The opaque solutions were then centrifuged at $3000 \mathrm{tr}^{-\mathrm{min}^{-1}}$ for $10 \mathrm{~min}$ or filtered on a filtering funnel with 5-13 $\mu \mathrm{m}$ porosity. The solid phase was recovered, dried under vacuum and weighted to determine the mass balance, while the percentage of total reducing sugars contained in the liquid phase was determined by adapted analytical procedures (see section 2.3). The experiments were performed in duplicates (20 wt \%) or triplicates (10 wt \%).

\subsection{Analysis: total reducing sugars, FT-IR and NMR}

The percentage of total reducing sugars (TRS) was determined with $1 \%$ dinitrosalicylic acid reagent (DNS) according to the Miller method [31]. A sample of $1.0 \mathrm{~mL}$ of the solution to be analysed was added to $1.0 \mathrm{~mL}$ of DNS reagent and boiled for 5 min precisely. Afterwards, $0.5 \mathrm{~mL}$ of a $40 \%$ potassium sodium tartrate solution was poured in order to keep the colouration of the product and cooled down in tap water to quench the oxidation reaction. Analyses were performed with an UV-Spectrophotometer (Shimadzu UV-1800) at a wavelength of 575 $\mathrm{nm}$. The concentration of reducing sugars was determined according to the standardisation performed on glucose. The range of experimental errors was $\pm 5 \%$ for the TRS analysis. The scan of a standard solution of 20 wt \% ionic liquid and water was performed between 700 and $300 \mathrm{~nm}$. None of the ionic liquids utilised absorbed at $575 \mathrm{~nm}$. Therefore, the ionic liquids were not separated from the main solution before being analysed.

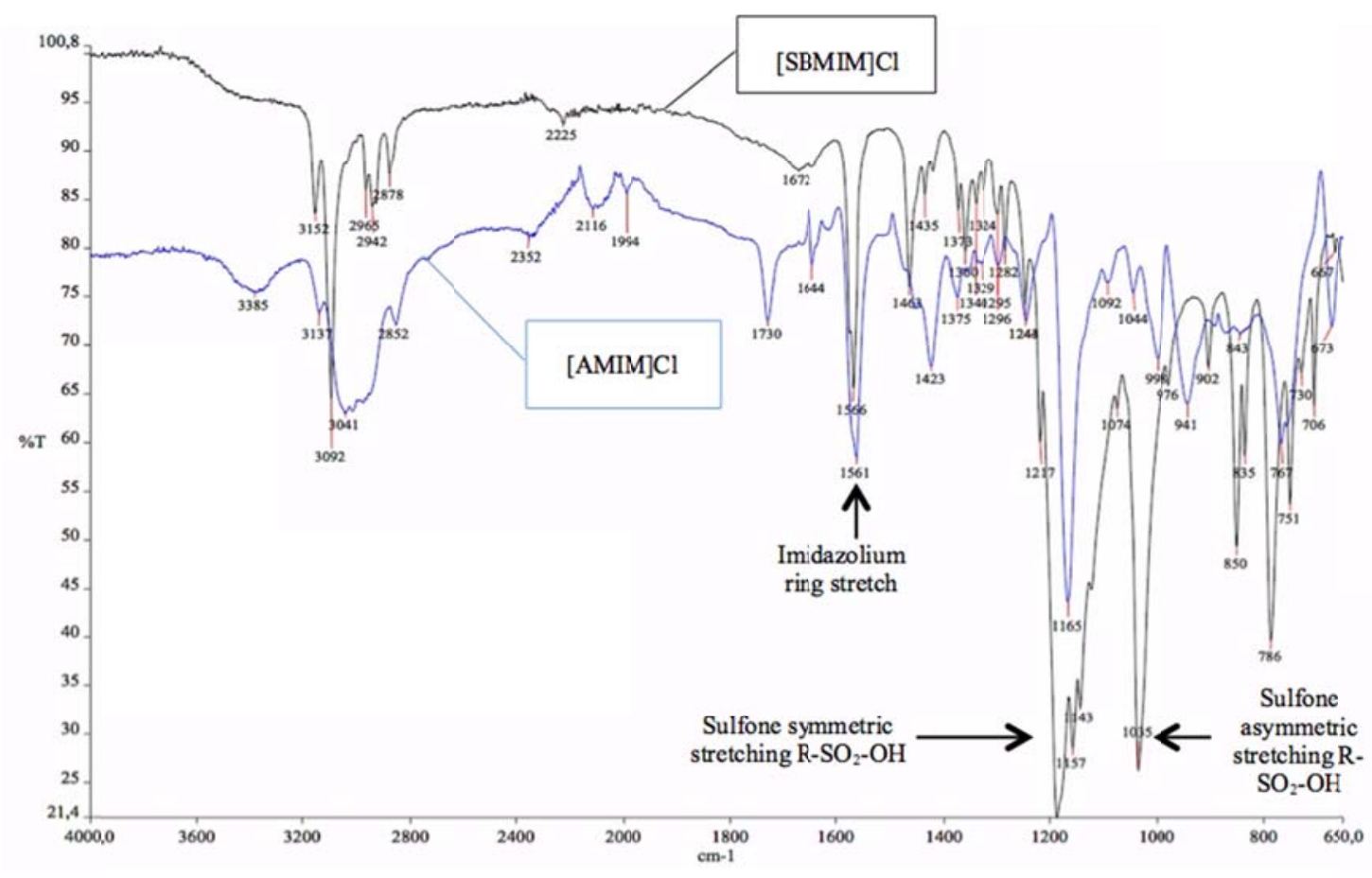


Fig. 2. FTIR spectra of $[\mathrm{AMIM}] \mathrm{Cl}$ and $[\mathrm{SBMIM}] \mathrm{Cl}$ after synthesis.

The spectroscopy of the ionic liquids were performed with a PerkinElmer Spectrum One Fourier Transform Infrared (FTIR) Spectrometer combined with a PerkinElmer Universal Attenuated Total Reflectance (ATR) Sampling Accessory, a sampling technique which offers a direct analysis of solid and liquid samples without any required preparation. The assignments of the bands and the corresponding wavelength of the ionic liquids are summarised in Table 1 and spectra in Fig. 2. First of all, the water-content in the ionic liquids can be characterised by the presence of two peaks at 3385 and $1644 \mathrm{~cm}^{-1}, \mathrm{O}-\mathrm{H}$ stretching and bending respectively. The intensity of these peaks depends on the quantity of water entrapped in the matrix of ionic liquids. [AMIM]Cl contained more water than $[$ SBMIM]Cl probably because of its high hygroscopic character. The FTIR spectra of [AMIM] $\mathrm{Cl}$ and that of the zwitterion utilised for the synthesis of [SBMIM]Cl corroborated with previous literature in [32] and [33] respectively.

${ }^{1}$ H NMR spectra of ILs were recorded with a Bruker DPX 200 instrument (200.13 MHz). Spectroscopic data of [AMIM]Cl was identical to the previous literature [14], [34], [35]: ${ }^{1} \mathrm{H}$ NMR $\left(200 \mathrm{MHz}, \mathrm{CDCl}_{3}\right){ }^{\mathrm{TM}}: 4.13(3 \mathrm{H}, \mathrm{s})$, $5.04\left(2 \mathrm{H}, \mathrm{d}, J_{H H}=6.3 \mathrm{~Hz}\right), 5.40-5.51(2 \mathrm{H}, \mathrm{m}), 5.97-6.10(1 \mathrm{H}, \mathrm{m}), 7.58\left(1 \mathrm{H}, \mathrm{t}, J_{H H}=1.8 \mathrm{~Hz}\right), 7.81\left(1 \mathrm{H}, \mathrm{t}, J_{H H}\right.$ $=1.8 \mathrm{~Hz}), 10.39(1 \mathrm{H}, \mathrm{s})$. However, a singlet at $3.38 \mathrm{ppm}$, corresponds to methanol residues from the cleaning steps. No peak was observed around 1.56 ppm, corresponding the $\mathrm{H}_{2} \mathrm{O}$ peak in $\mathrm{CDCl}_{3}$ [36]. The spectroscopic data of [SBMIM]Cl followed the literature [37]: ${ }^{1} \mathrm{H}$ NMR $\left(200 \mathrm{MHz}, \mathrm{D}_{2} \mathrm{O}\right){ }^{\text {тм}}: 1.72(2 \mathrm{H}, \mathrm{m}), 1.98(2 \mathrm{H}, \mathrm{m}), 2.91$ $\left(2 \mathrm{H}, \mathrm{t} J_{H H}=7.6 \mathrm{~Hz}\right), 3.86(3 \mathrm{H}, \mathrm{s}), 4.22\left(2 \mathrm{H}, \mathrm{t}, J_{H H}=7.0 \mathrm{~Hz}\right) 7.41\left(1 \mathrm{H}, \mathrm{t}, J_{H H}=1.8 \mathrm{~Hz}\right), 7.47\left(1 \mathrm{H}, \mathrm{t}, J_{H H}=1.8\right.$ $\mathrm{Hz}), 8.72(1 \mathrm{H}, \mathrm{s})$. 


\begin{tabular}{|c|c|c|}
\hline $\begin{array}{l}\text { Ionic } \\
\text { Liquid } \\
\mathrm{s}\end{array}$ & Band assignments & Wavelength $\left(\mathrm{cm}^{-1}\right)$ \\
\hline \multirow[t]{7}{*}[\mathrm{SBMIM}]{$\mathrm{Cl}$} & Alkyl C-H stretching & $2965,2942 \& 2878$ \\
\hline & Imidazole ring stretching & 1566 \\
\hline & Sulfone symmetric stretching $\mathrm{R}-\mathrm{SO}_{2}-\mathrm{OH}$ & 1175 \\
\hline & Imidazole $\mathrm{H}-\mathrm{C}-\mathrm{C} \& \mathrm{H}-\mathrm{C}-\mathrm{N}$ bending & 1157 \\
\hline & Sulfone asymmetric stretching $\mathrm{R}-\mathrm{SO}_{2}-\mathrm{OH}$ & 1035 \\
\hline & In-plane imidazole ring bending & 850 \\
\hline & Out-of-plane imidazole ring $\mathrm{C}-\mathrm{H}$ bending & 786 \\
\hline \multirow[t]{6}{*}[\mathrm{AMIM}]{$\mathrm{Cl}$} & $\mathrm{O}-\mathrm{H}$ stretching - water content & 3385 \\
\hline & Broad peak contains alkyl C-H stretching & $3040-2870$ \\
\hline & $\mathrm{O}-\mathrm{H}$ bending - water content & 1644 \\
\hline & Imidazole ring stretching & 1561 \\
\hline & Imidazole $\mathrm{H}-\mathrm{C}-\mathrm{C} \& \mathrm{H}-\mathrm{C}-\mathrm{N}$ bending & 1165 \\
\hline & Out-of-plane imidazole ring $\mathrm{C}-\mathrm{H}$ bending & 767 \\
\hline
\end{tabular}

Table 1 Band assignments of the ionic liquids [SBMIM]Cl and [AMIM]Cl

\section{Results and discussion}

\subsection{Comparison of the ionic liquids for the dissolution and depolymerisation of starch}

At $80{ }^{\circ} \mathrm{C}$, a $15 \mathrm{wt} \%$ solution of starch in [AMIM]Cl can be totally dissolved within 40 min [34] whilst [SBMIM]Cl can also be dissolved up to $10 \mathrm{wt} \%$ of cellulose at room temperature in a shorter time period [21]. At first, the maximal weight percentage of dissolution of our starch materials in both ionic liquids was determined. The simplest matrix, i.e. potato starch, was added in $0.1 \mathrm{~g}$ increments to [AMIM]Cl at $80{ }^{\circ} \mathrm{C}$ until the dissolution was complete up to $20 \mathrm{wt} \%$. The observed instantaneous dissolution renders this ionic liquid as an attractive prospect and certainly offers a promising future in the field of biomass valorisation. However, in parallel, $1.0 \mathrm{~g}$ of potato starch was added at once to a $[\mathrm{AMIM}] \mathrm{Cl}$ solution at $80{ }^{\circ} \mathrm{C}$. In this case, $15 \mathrm{~min}$ of stirring was also needed to reach a clear $20 \mathrm{wt} \%$ mixture. Xu et al [34] showed that corn starch could be dissolved up to $15 \mathrm{wt} \%$ in [AMIM]Cl within $40 \mathrm{~min}$ at $80{ }^{\circ} \mathrm{C}$ and up to $20 \mathrm{wt} \%$ within 15 min at $100{ }^{\circ} \mathrm{C}$ under an argon atmosphere. Although our results differ to some extent from the studies mentioned above, they can be explained by the water-content of the ionic liquid, not defined in their study. It is highly probable that our ionic 
liquid contained a higher amount of water than Wu et al., diminishing subsequently the dissolution efficiency. It is indeed well known that water-content can disrupt the carbohydrate dissolution in an ionic liquid and lead to a heterogeneous medium [38]. The dissolution of potato starch in [SBMIM]Cl required a longer time period than in [AMIM]Cl; in fact, $20 \mathrm{wt} \%$ potato starch in [SBMIM] Cl did not even stir after several minutes at $80{ }^{\circ} \mathrm{C}$ with an increased viscosity. Potato starch is mainly composed of amylose and amylopectin compared to wet potato sludge and dry potato sludge which contain some proteins, minerals and vitamins. Therefore, the previous protocol was not applied to these raw materials. Their total dissolution in ionic liquids was not observed probably due of the presence of these natural compounds. Wet and dry potato sludge were added to their respective ionic liquids at once. Both ionic liquids are attractive for the dissolution of potato starch, however the results about the depolymerisation were radically different. The TRS yield of pure starch reached $54 \%$ with the Brønsted-acidic ionic liquid at $80{ }^{\circ} \mathrm{C}$ (table 2 , entry 3 ) and only $6 \%$ in the [AMIM]Cl (table 2, entry 17 ). The absence of intrinsic acidity and additional acidic catalyst in [AMIM]Cl is certainly the main reason of a low TRS value. However, the existence of this small amount of TRS can be explained. Indeed, it is known that some first and second generations imidazolium-based ionic liquids possess a weak acidity often tied to the nature of counter-anion, making it reasonable to reach a low $6 \%$ of depolymerisation [39], [40]. The first generation of ionic liquids possess a halide anion (i.e. 1-allyl-3-methylimidazolium chloride - [AMIM]Cl), whereas the second generation undergo a metathesis of the halide anion into a more water stable one (i.e. 1-allyl-3methylimidazolium acetate - [AMIM]OAc [41]. TSIL are considered as part of the 'third generation' of ionic liquids due to their functionalised moieties (i.e. 1-(4-sulfobutyl)-3-methylimidazolium chloride - [SBMIM]Cl) [42], [43]. The TSIL selected possesses a Brønsted-acid and can play the role of both the solvent and the catalyst. [SBMIM] $\mathrm{Cl}$ has an acidic function for the hydrolysis, while $[\mathrm{AMIM}] \mathrm{Cl}$ is a neutral ionic liquid.

\subsection{Effect of temperature on the depolymerisation of potato starch}

Temperature also plays an important role in the efficiency of depolymerisation of starch. In order to compare the results with our previous study performed in an aqueous acidic medium [2], the depolymerisation of the three starch-based starting materials was performed in an ionic liquid medium ranging between $60-90{ }^{\circ} \mathrm{C}$. Temperature has an effect on the viscosity of the ionic liquids by decreasing it [44]. The use of an ionic liquid allows work to be conducted at higher operating temperatures than those used in aqueous sulphuric acid. Indeed, in the latter, the starch easily undergoes gelatinisation at around $65{ }^{\circ} \mathrm{C}$, making any further transformation 
difficult. Reactions were performed in $20 \%(\mathrm{w} / \mathrm{w})$ of water on a $10 \mathrm{wt} \%$ solution of all three starch-based materials in [SBMIM]Cl. Temperature effect on the depolymerisation is shown in Fig. 3. It has been previously shown that [SBMIM]Cl possess a higher ability to dissolve cellulose than neutral ionic liquids at $100{ }^{\circ} \mathrm{C}[21]$. Whatever the nature and composition of the starch-based material, the highest TRS yield was obtained at $80{ }^{\circ} \mathrm{C}$. $54 \%$ of potato starch was converted into reducing sugars at $80{ }^{\circ} \mathrm{C}$ (table 2 , entry 3 ), which corroborates well with the results obtained by Amarasekara and Owereh [21] on the hydrolysis of cellulose with an identical ionic liquid.

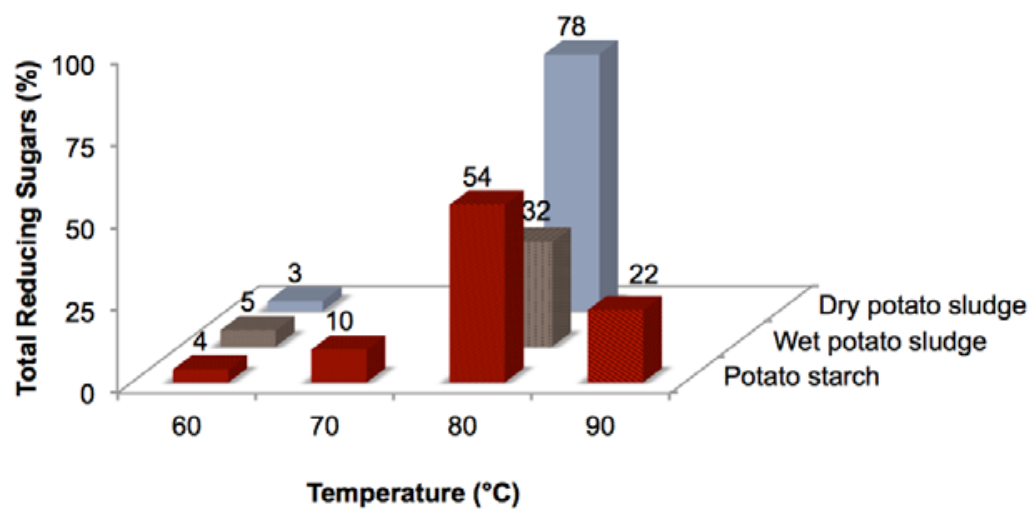

Fig.3. Effect of dissolution temperature on the depolymerisation of the three starting materials in $10 \mathrm{wt} \%$ [SBMIM]Cl for 120 min under mechanical stirring. 


\begin{tabular}{|c|c|c|c|c|c|}
\hline Experiment & Raw materials & Techniques & $W t \%{ }^{e}$ & Temperature $\left({ }^{\circ} \mathbf{C}\right)$ & Yield $_{\text {TRS }}(\%)$ \\
\hline 1 & [SBMIM]Cl-PS & Mech. Stir. ${ }^{a}$ & 10 & 60 & 6 \\
\hline 2 & [SBMIM]Cl - PS & Mech. Stir. ${ }^{\mathrm{a}}$ & 10 & 70 & 10 \\
\hline 3 & [SBMIM]Cl - PS & Mech. Stir. ${ }^{a}$ & 10 & 80 & 54 \\
\hline 4 & [SBMIM]Cl-PS & Mech. Stir. ${ }^{a}$ & 10 & 90 & 22 \\
\hline 5 & [SBMIM]Cl - WPS & Mech. Stir. ${ }^{a}$ & 10 & 80 & 32 \\
\hline 6 & [SBMIM]Cl - DPS & Mech. Stir. ${ }^{\mathrm{a}}$ & 10 & 80 & 78 \\
\hline 7 & [SBMIM]Cl - PS & Microwave $^{b}$ & 10 & 60 & 61 \\
\hline 8 & [SBMIM]Cl - WPS & Microwave $^{b}$ & 10 & 60 & 19 \\
\hline 9 & [SBMIM]Cl - DPS & Microwave $^{b}$ & 10 & 60 & 67 \\
\hline 10 & {$[\mathrm{SBMIM}] \mathrm{Cl}-\mathrm{PS}$} & $\mathrm{US}-\mathrm{LF}^{\mathrm{c}}$ & 10 & 60 & 9 \\
\hline 11 & [SBMIM]Cl - WPS & $\mathrm{US}-\mathrm{LF}^{\mathrm{c}}$ & 10 & 60 & 5 \\
\hline 12 & [SBMIM]Cl - DPS & $\mathrm{US}-\mathrm{LF}^{\mathrm{c}}$ & 10 & 60 & 15 \\
\hline 13 & [SBMIM]Cl - PS & Mech. Stir. ${ }^{a}$ & 20 & 80 & 6 \\
\hline 14 & [SBMIM]Cl - WPS & Mech. Stir. ${ }^{a}$ & 20 & 80 & 4 \\
\hline 15 & [SBMIM]Cl - DPS & Mech. Stir. ${ }^{\text {a }}$ & 20 & 80 & 11 \\
\hline 16 & {$[\mathrm{AMIM}] \mathrm{Cl}-\mathrm{PS}$} & Mech. Stir. ${ }^{a}$ & 10 & 60 & 12 \\
\hline 17 & [AMIM]Cl - PS & Mech. Stir. ${ }^{\mathrm{a}}$ & 10 & 80 & 6 \\
\hline 18 & [AMIM]Cl - PS & Mech. Stir. ${ }^{a}$ & 20 & 80 & 6 \\
\hline $19^{\mathrm{d}}$ & $\mathrm{H}_{2} \mathrm{SO}_{4} 3 \mathrm{M}-\mathrm{PS}$ & Mech. Stir. ${ }^{\text {a }}$ & 3 & 60 & 36 \\
\hline $20^{d}$ & $\mathrm{H}_{2} \mathrm{SO}_{4} 3 \mathrm{M}-\mathrm{WPS}$ & Mech. Stir. ${ }^{\text {a }}$ & 3 & 60 & 9 \\
\hline $21^{\mathrm{d}}$ & $\mathrm{H}_{2} \mathrm{SO}_{4} 3 \mathrm{M}-\mathrm{DPS}$ & Mech. Stir. ${ }^{a}$ & 3 & 60 & 29 \\
\hline
\end{tabular}

Table 2 Yields of reducing sugars of the depolymerisation of the three starting materials (PS for Potato starch, WPS for Wet potato sludge and DPS for Dry potato sludge)

${ }^{a}$ mechanical stirring with hot plate stirrer

${ }^{\mathrm{b}} 60 \mathrm{~min}$ of irradiation

${ }^{c}$ ultrasound low frequency (24kHz ultrasonic bath)

${ }^{d}$ previous research [4]

${ }^{\mathrm{e}}$ weight percentage of starting material/ionic liquid

\subsection{Comparison of mechanical stirring with microwave and low frequency ultrasound} irradiations

Microwave and ultrasound irradiations may enhance the hydrolysis of carbohydrates into sugars due to their own specific effects. With microwave irradiation, a reaction media is heated from the inner to the outer layer and can 
reduce the reaction time from hours to minutes [2]. Low frequency ultrasound irradiation generates shock waves, which allow an efficient stirring of the reaction medium and increase the total reducing sugar content [2].

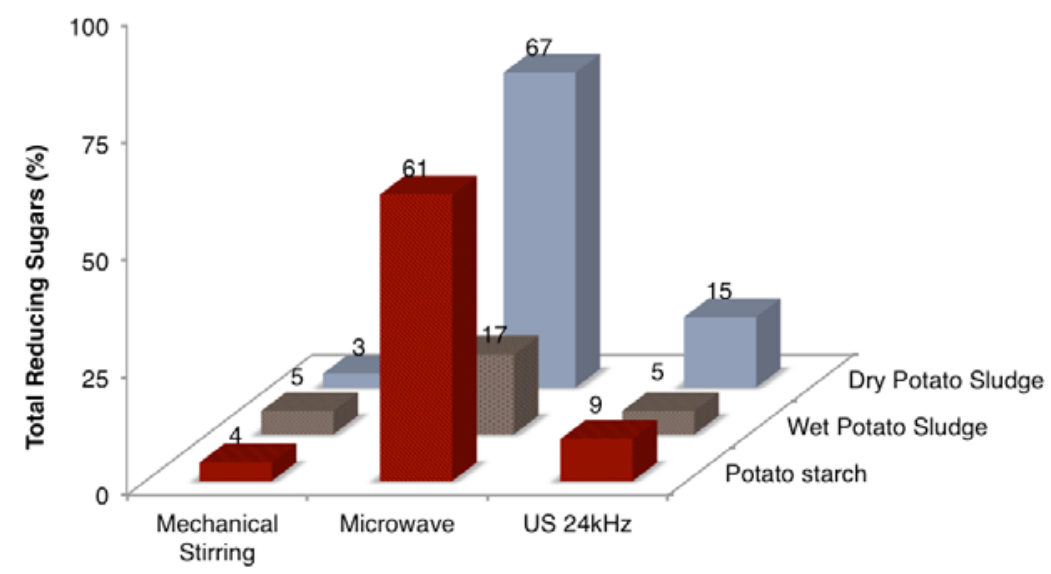

Fig. 4. Yields of the total reducing sugars obtained by the depolymerisation tech- niques of the three starting materials in $10 / 12 \mathrm{wt} \%$ [SBMIM] $\mathrm{Cl}$ at $60{ }^{\circ} \mathrm{C}$ for $120 \mathrm{~min}$ (60 $\mathrm{min}$ for microwave).

Unfortunately, due to the utilisation of the ultrasound bath, the hydrolysis could not be performed at the optimum temperature $\left(80^{\circ} \mathrm{C}\right)$ determined in the previous section with the Brønsted-acidic ionic liquid. Filled with distilled water, maintaining such a high and constant temperature without changing some key parameters of the ultrasound is particularly difficult. At $80^{\circ} \mathrm{C}$, a parasite phenomenon called 'vaporous cavitation' can appear and dramatically decreases the efficiency of acoustic cavitation. Natural bubbles of vaporous water appear, displaying a much higher diameter than cavitation bubbles. The latter can undergo coalescence with the former, leading to a dramatic decrease or even the suppression of the necessary mechanical effects brought up by the collapse of cavitation bubbles, expected to contribute to depolymerisation. The raw materials were thus irradiated for $120 \mathrm{~min}$ at $60{ }^{\circ} \mathrm{C}$ with a synthesis microwave and a low frequency ultrasonic bath for comparison with conventional stirring; results are shown in Fig. 4. Even if the temperature has been decreased, a high loss of efficiency can be observed with this indirect mode irradiation; the energy being dissipated in the water bath and only 9,5 and $15 \%$ of reducing sugars of potato starch, wet potato sludge and dry potato sludge, respectively, were reached. An ultrasonic bath may not be powerful enough to allow the mixing of a highly heterogeneous and viscous system that would require the use of an ultrasonic probe, directly immersed in the solution for a direct irradiative mode. Our previous research performed using a sulphuric acid medium provided similar results [2].

The depolymerisation under microwave irradiation offered the highest TRS content within 60 min regardless of the starting material. Due to their strong polar character, ionic liquids are a very suitable medium for microwave 
irradiation. This is confirmed by the fact that for potato starch, a temperature of $60{ }^{\circ} \mathrm{C}$ was high enough to generate engaging amounts of reducing sugars. However, the brown aspect of the solution after microwave irradiation of the two other starting materials could be explained by the caramelisation reaction. Caramelisation of short-chain or monomeric sugars is known as the Maillard reaction. This was also observed by Lajunen et al. [45] for the depolymerisation of barley starch in imidazolium-based ionic liquids under microwave irradiation. An appropriate Plexiglas helix-ended rod was introduced into the microwave reactor to limit the effect of thermal gradient and local hot spots, but this remained inefficient and could not attenuate caramelisation. However, the combination of rapid heating in an ionic liquid medium increased the yield of reducing sugars whilst reducing the reaction time. A set temperature can be reached in a really short time through consecutive rotation of the ionic molecules. This renders the combination of microwave heating/ionic liquid as very attractive. For all raw materials, the total reducing sugars reached 3 to 10 fold under microwave irradiation than with conventional heating in similar conditions. Microwave technology has previously been employed for the conversion of cellulose into reducing sugars or 5-HMF in ionic liquids [46], [47], [48], [49] or for the production of furfural from sugars with Brønsted-acidic ionic liquids [50]; no reports exist for starch in ionic liquids conditions. The conversion of cellulose into reducing sugars reached $48 \%$ in only 8 min of irradiation with a HY zeolite catalyst at $180{ }^{\circ} \mathrm{C}$ [46]. In this study, $61 \%$ of potato starch was converted into reducing sugars under microwave irradiation with the Brønsted-acidic ionic liquid, and only $4 \%$ using conventional heating.

\subsection{Effect of water-content for the depolymerisation of starch in [SBMIM]Cl}

Ionic liquids display natural high viscosities (i.e. the viscosity of 1-butyl-3-methylimidazolium iodine [BMIM]I, 1-butyl-3-methylimidazolium tetrafluoroborate $\quad[\mathrm{BMIM}] \mathrm{BF}_{4}, \quad$ and 1-butyl-3-methylimidazolium bis(trifluoromethylsulfonyl)imide [BMIM]NTf 2 are 400, 280 and $50 \mathrm{mPa} . \mathrm{s}$, respectively [51], [52]); the addition of a certain weight percentage of starch-based material renders the solution even more viscous, making it difficult to stir reacting solution. As a typical example, a $20 \mathrm{wt} \%$ of raw material/ionic liquid series was performed with $10 \%(\mathrm{w} / \mathrm{w})$ of water added at $80{ }^{\circ} \mathrm{C}$ for $120 \mathrm{~min}$. The low TRS yield of 6,4 and $11 \%$ for potato starch, wet potato sludge and dry potato sludge respectively, are observed due to the mass transfer limitations with high weight percentage. In addition, the presence of water is required to dissociate the sulfonic acid group to enable the acidic depolymerisation of the starch molecules. We subsequently studied the impact of the added water on the depolymerisation rate of 2 of the 3 starch materials used in this study, the native potato starch and 
the wet potato sludge. The increase of weight percentage of the ratio between raw material/ionic liquid and the water content are important factors for scaling up. As shown in Fig. 5, the optimum weight percentage of $\mathrm{H}_{2} \mathrm{O}$ was $33 \%$ for wet potato sludge to reach $43 \%$ of reducing sugars whilst $45 \%$ (w/w) of $\mathrm{H}_{2} \mathrm{O}$ was necessary for a total hydrolysis of potato starch. One molecule of water is consumed for every broken glycosidic bond of starch; therefore water is required for the hydrolysis. The results confirm that water can improve the hydrolysis reaction of starch into sugars in a Brønsted-acidic ionic liquid, which corroborates with previous reports [53]. The authors suggested that aqueous Brønsted-acidic ionic liquids promoted the attack of the glycosidic bonds of cellulose for its conversion into $\alpha$-glucose. A total hydrolysis of potato starch was achieved probably because $\alpha$-glycosidic bonds are easily cleaved compare to $\beta$-glycosidic bonds (cellulose). The aqueous ionic liquid was able to dissolve potato starch, whilst the key to the hydrolysis of the Brønsted-acidic function is in the form of a superacid and may be considered as a simple hydrolysis.

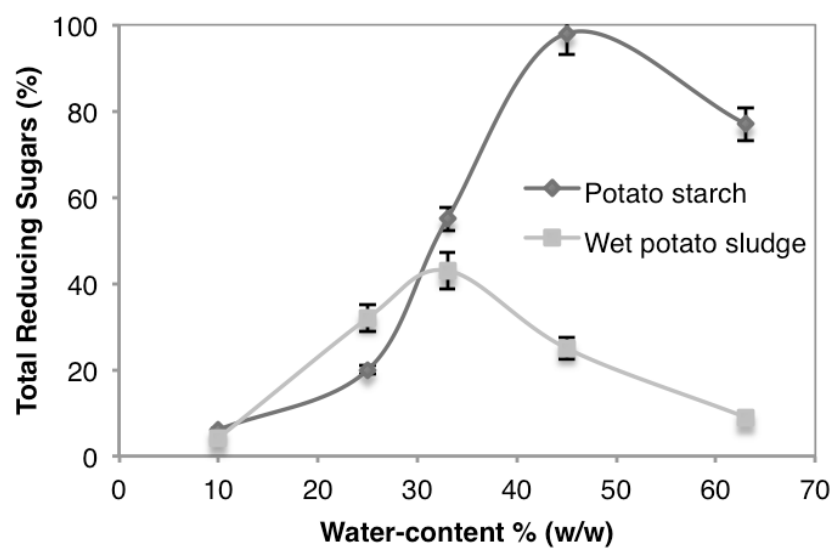

Fig. 5. Yields of total reducing sugars produced during the depolymerisation of potato starch and wet potato sludge in aqueous [SBMIM]Cl ( 20 -wt $\%$ solution- $-0.50 \mathrm{~g}$ of ionic liquid, $0.10 \mathrm{~g}$ of dry raw materials). Solutions were stirred for $120 \mathrm{~min}$ at $80^{\circ} \mathrm{C}$.

\section{Conclusion}

In this study, we optimised the parameters to dissolve and depolymerise a starch-based industrial waste in ionic liquids. [AMIM] $\mathrm{Cl}$ appeared to be more suitable for the dissolution of potato starch due to the imidazolium ring and the chloride anion. However, [SBMIM]Cl dissolved potato starch and depolymerised the starting materials into reducing sugars in one step in an aqueous Brønsted-acidic medium. [SBMIM]Cl played the role of dual solvent/catalyst and followed the requirements of the sustainable chemistry. Temperature acted as a relevant factor for the depolymerisation of starch in conventional heating. The yield of reducing sugars under the optimum conditions (conventional heating in aqueous [SBMIM] Cl $-33 \%(w / w)$ of $\mathrm{H}_{2} \mathrm{O}$, a solution of $20 \mathrm{wt} \%$, 
$120 \mathrm{~min}$ of stirring at $80{ }^{\circ} \mathrm{C}$ ), reached $43 \%$ for a complex wet matrix - wet potato sludge. Overall, water disrupts the dissolution process of carbohydrate in ionic liquids, but the method described herein generated the greatest yield of reducing sugars. The addition of water overcame the high viscosity of a $20 \mathrm{wt} \%$ solution. Finally, microwaves only appear to reduce the reaction time by reaching the required temperature in a short time period.

\section{Acknowledgement}

The authors would like to acknowledge the Academy of Finland (Project no 124331), the French Rhône-Alpes Region for their financial support and the Fortum Foundation for awarding a grant to A. Hernoux. Furthermore, the authors would like to thank Mr. Jaakko Pulkkinen for the preparation and optimisation of the ionic liquids. UBIOCHEM Cost Action is gratefully acknowledged.

\section{References}

[1] J. H. Clark et F. Deswarte, Introduction to Chemicals from Biomass. John Wiley \& Sons, 2011.

[2] A. Hernoux, J.-M. Lévêque, U. Lassi, S. Molina-Boisseau, et M.-F. Marais, « Conversion of a nonwater soluble potato starch waste into reducing sugars under non-conventional technologies », Carbohydrate Polymers, vol. 92, nº 2, p. 2065-2074, févr. 2013.

[3] Alpha L. Morehouse, Ronald C. Malzahn, et John T. Day, « Hydrolysis of Starch », 366336916-mai1972.

[4] V. Myllymaki et R. Aksela, « Depolymerization Method », US 2009/0032015 A127-sept-2006.

[5] J. Singh, L. Kaur, et O. J. McCarthy, «Factors influencing the physico-chemical, morphological, thermal and rheological properties of some chemically modified starches for food applications-A review », Food Hydrocolloids, vol. 21, n 1, p. 1-22, janv. 2007.

[6] J. Shen, H. Wang, H. Liu, Y. Sun, et Z. Liu, « Brønsted acidic ionic liquids as dual catalyst and solvent for environmentally friendly synthesis of chalcone », Journal of Molecular Catalysis A: Chemical, vol. 280, $\mathrm{n}^{\circ}$ 1-2, p. 24-28, févr. 2008. 
[7] A. R. Hajipour et F. Rafiee, « Acidic Bronsted Ionic Liquids », Organic Preparations and Procedures International, vol. 42, $\mathrm{n}^{\mathrm{o}} 4$, p. 285-362, 2010.

[8] K. Wilpiszewska et T. Spychaj, «Ionic liquids: Media for starch dissolution, plasticization and modification », Carbohydrate Polymers, vol. 86, n 2, p. 424-428, août 2011.

[9] C. Chiappe et D. Pieraccini, «Ionic liquids: solvent properties and organic reactivity », Journal of Physical Organic Chemistry, vol. 18, n 4, p. 275-297, 2005.

[10] M. E. Zakrzewska, E. Bogel-Łukasik, et R. Bogel-Łukasik, « Solubility of Carbohydrates in Ionic Liquids », Energy \& Fuels, vol. 24, nº 2, p. 737-745, févr. 2010.

[11] R. C. Remsing, R. P. Swatloski, R. D. Rogers, et G. Moyna, « Mechanism of cellulose dissolution in the ionic liquid 1-n-butyl-3-methylimidazolium chloride: a 13C and 35/37Cl NMR relaxation study on model systems », Chem. Commun., nº 12, p. 1271-1273, mars 2006.

[12] Q. Ren, J. Wu, J. Zhang, J. He, et M. Guo, « Synthesis of 1-Ally1, 3-methylimidazolium-Based RoomTemperature Ionic Liquid and Preliminary Study of Its Dissolving Cellulose », Acta Polymerica Sinica, $\mathrm{n}^{\mathrm{o}} 3, \mathrm{p}$. 448-451, 2003.

[13] F. Guo, Z. Fang, C. C. Xu, et R. L. Smith Jr., « Solid acid mediated hydrolysis of biomass for producing biofuels », Progress in Energy and Combustion Science, vol. 38, nº 5, p. 672-690, oct. 2012.

[14] K. Lappalainen, J. Kärkkäinen, J. Panula Perälä, M. Lajunen, K. Lappalainen, J. Kärkkäinen, J. Panula Perälä, et M. Lajunen, « Preparation of water soluble starch oligomers from variable starch species in 1 allyl 3 methylimidazolium chloride, Preparation of water soluble starch oligomers from variable starch species in 1 allyl 3 methylimidazolium chloride », Starch Stärke, vol. 64, n 4, p. 263-271, avr. 2012.

[15] A. C. Cole, J. L. Jensen, I. Ntai, K. L. T. Tran, K. J. Weaver, D. C. Forbes, et J. H. Davis, « Novel Brønsted Acidic Ionic Liquids and Their Use as Dual Solvent-Catalysts », J. Am. Chem. Soc., vol. 124, n 21, p. 5962-5963, mai 2002.

[16] R. Sugimura, K. Qiao, D. Tomida, et C. Yokoyama, «Immobilization of acidic ionic liquids by copolymerization with styrene and their catalytic use for acetal formation », Catalysis Communications, vol. 8, $n^{\circ} 5$, p. 770-772, mai 2007. 
[17] K. E. Johnson, R. M. Pagni, et J. Bartmess, « Brønsted Acids in Ionic Liquids: Fundamentals, Organic Reactions, and Comparisons », Monatshefte für Chemie / Chemical Monthly, vol. 138, n 11, p. 1077-1101, 2007.

[18] X. Liu, H. Ma, Y. Wu, C. Wang, M. Yang, P. Yan, et U. Welz-Biermann, « Esterification of glycerol with acetic acid using double SO3H-functionalized ionic liquids as recoverable catalysts », Green Chem., vol. $13, \mathrm{n}^{\mathrm{o}} 3$, p. 697-701, mars 2011 .

[19] L. Myles, N. Gathergood, et S. J. Connon, « The catalytic versatility of low toxicity dialkyltriazolium salts: in situ modification facilitates diametrically opposed catalysis modes in one pot », Chem. Commun., vol. 49, $\mathrm{n}^{\mathrm{o}} 46$, p. 5316-5318, mai 2013.

[20] C. Hardacre, J. D. Holbrey, M. Nieuwenhuyzen, et T. G. A. Youngs, « Structure and Solvation in Ionic Liquids », Acc. Chem. Res., vol. 40, nº 11, p. 1146-1155, nov. 2007.

[21] A. S. Amarasekara et O. S. Owereh, « Hydrolysis and Decomposition of Cellulose in Brönsted Acidic Ionic Liquids Under Mild Conditions », Ind. Eng. Chem. Res., vol. 48, n 22, p. 10152-10155, 2009.

[22] A. S. Amarasekara et B. Wiredu, «Degradation of Cellulose in Dilute Aqueous Solutions of Acidic Ionic Liquid 1-(1-Propylsulfonic)-3-methylimidazolium Chloride, and p-Toluenesulfonic Acid at Moderate Temperatures and Pressures », Ind. Eng. Chem. Res., vol. 50, n 21, p. 12276-12280, 2011.

[23] A. S. Amarasekara et B. Wiredu, «Brönsted Acidic Ionic Liquid 1-(1-Propylsulfonic)-3methylimidazolium-Chloride Catalyzed Hydrolysisof D-Cellobiose in Aqueous Medium », International Journal of Carbohydrate Chemistry, vol. 2012, p. 1-6, 2012.

[24] T. J. Mason et J. P. Lorimer, Applied sonochemistry: the uses of power ultrasound in chemistry and processing. Wiley-VCH, 2002.

[25] Loupy, Microwaves in Organic Synthesis - Second, completely revised and Enlarged Edition, WileyCH., vol. Volume 1. 2006.

[26] A. Hernoux-Villière, «Catalytic depolymerisation of starch-based industrial waste: use of nonconventional activation methods and novel reaction media », University of Oulu - Université de Savoie, 2013.

[27] H. Zhang, J. Wu, J. Zhang, et J. He, « 1-Allyl-3-methylimidazolium Chloride Room Temperature Ionic Liquid: A New and Powerful Nonderivatizing Solvent for Cellulose », Macromolecules, vol. 38, $\mathrm{n}^{\mathrm{O}}$ 20, p. 82728277, oct. 2005. 
[28] N. Srivastava, M. Shukla, et S. Saha, «An unusal effect of charcoal on the purification of alkylimidazolium iodide room temperature ionic liquids », Indian journal of chemistry. Section A, Inorganic, bio-inorganic, physical, theoretical \& analytical chemistry, vol. 49, nº 5, p. 757-761, 2010.

[29] J. Gui, X. Cong, D. Liu, X. Zhang, Z. Hu, et Z. Sun, « Novel Brønsted acidic ionic liquid as efficient and reusable catalyst system for esterification », Catalysis Communications, vol. 5, nº 9, p. 473-477, sept. 2004.

[30] C. M. Gordon, M. J. Muldoon, M. Wagner, C. Hilgers, J. H. Davis, et P. Wasserscheid, « Synthesis and Purification », in Ionic Liquids in Synthesis, P. Wasserscheid et T. Welton, Éd. Wiley-VCH Verlag GmbH \& Co. KGaA, 2008, p. 7-55.

[31] G. L. Miller, « Use of Dinitrosalicylic Acid Reagent for Determination of Reducing Sugar », Analytical Chemistry, vol. 31, n 3, p. 426-428, mars 1959.

[32] S. Ramesh, R. Shanti, et E. Morris, « Plasticizing effect of 1-allyl-3-methylimidazolium chloride in cellulose acetate based polymer electrolytes », Carbohydrate Polymers, vol. 87, nº 4, p. 2624-2629, mars 2012.

[33] T. Peppel et M. Köckerling, «Imidazolium-Based Zwitterionic Butane-1-sulfonates: Synthesis and Properties of 4-(1-(2-Cyanoethyl)imidazolium)butane-1-sulfonate and Crystal Structures of 4-(1Alkylimidazolium)butane-1-sulfonates (Alkyl = Methyl, Ethyl, Propyl)», Zeitschrift für anorganische und allgemeine Chemie, vol. 637, nº 7-8, p. 870-874, 2011.

[34] Q. Xu, J. F. Kennedy, et L. Liu, « An ionic liquid as reaction media in the ring opening graft polymerization of [epsilon]-caprolactone onto starch granules », Carbohydrate Polymers, vol. 72, $\mathrm{n}^{\circ} 1$, p. 113121, avr. 2008.

[35] W. Ning, Z. Xingxiang, L. Haihui, et H. Benqiao, « 1-Allyl-3-methylimidazolium chloride plasticizedcorn starch as solid biopolymer electrolytes », Carbohydrate Polymers, vol. 76, nº 3, p. 482-484, 2009.

[36] H. E. Gottlieb, V. Kotlyar, A. Nudelman, et others, « NMR chemical shifts of common laboratory solvents as trace impurities », Journal of Organic Chemistry, vol. 62, n 21, p. 7512-7515, 1997.

[37] F. Tao, H. Song, et L. Chou, «Catalytic conversion of cellulose to chemicals in ionic liquid », Carbohydrate Research, vol. 346, nº 1, p. 58-63, janv. 2011.

[38] M. Mazza, D.-A. Catana, C. Vaca-Garcia, et C. Cecutti, « Influence of water on the dissolution of cellulose in selected ionic liquids », Cellulose, vol. 16, n² 2, p. 207-215, 2009. 
[39] T. Welton, « Room-temperature ionic liquids. Solvents for synthesis and catalysis », Chemical reviews, vol. 99, p. 2071-2084, 1999.

[40] K. R. Seddon, A. Stark, M. J. Torres, et others, « Influence of chloride, water, and organic solvents on the physical properties of ionic liquids », Pure Appl. Chem, vol. 72, n 12, p. 2275-2287, 2000.

[41] J. S. Wilkes, P. Wasserscheid, et T. Welton, «Introduction », in Ionic Liquids in Synthesis, P. Wasserscheid et T. Welton, Éd. Wiley-VCH Verlag GmbH \& Co. KGaA, 2008, p. 1-6.

[42] J. H. Davis, « Task-specific ionic liquids », Chemistry letters, vol. 33, nº 9, p. 1072-1077, 2004.

[43] R. Giernoth, « Task-Specific Ionic Liquids », Angewandte Chemie International Edition, vol. 49, n 16, p. $2834-2839,2010$.

[44] H. Weingärtner, «Understanding Ionic Liquids at the Molecular Level: Facts, Problems, and Controversies », Angewandte Chemie International Edition, vol. 47, nº 4, p. 654-670, 2008.

[45] K. Lappalainen, J. Kärkkäinen, et M. Lajunen, « Dissolution and depolymerization of barley starch in selected ionic liquids », Carbohydrate Polymers, $\mathrm{n}^{\circ} 0$.

[46] Z. Zhang et Z. K. Zhao, " Solid acid and microwave-assisted hydrolysis of cellulose in ionic liquid », Carbohydrate Research, vol. 344, nº 15, p. 2069-2072, oct. 2009.

[47] Z. Zhang et Z. K. Zhao, « Microwave-assisted conversion of lignocellulosic biomass into furans in ionic liquid », Bioresource Technology, vol. 101, nº 3, p. 1111-1114, févr. 2010.

[48] C. Li, Z. Zhang, et Z. K. Zhao, « Direct conversion of glucose and cellulose to 5-hydroxymethylfurfural in ionic liquid under microwave irradiation », Tetrahedron Letters, vol. 50, n 38, p. 5403-5405, sept. 2009.

[49] X. Qi, M. Watanabe, T. M. Aida, et R. L. Smith, «Fast Transformation of Glucose and Di/Polysaccharides into 5-Hydroxymethylfurfural by Microwave Heating in an Ionic Liquid/Catalyst System », ChemSusChem, vol. 3, nº 9, p. 1071-1077, 2010.

[50] J. C. Serrano-Ruiz, J. M. C. Perez, M. Francavilla, C. Menendez, A. B. Garcia, A. A. R. REYES, R. Luque, et E. J. Garcia-Suarez, «Efficient microwave-assisted production of furfural from C5 sugars in aqueous media catalysed by Brönsted acidic ionic liquids », Catalysis Science \& Technology, 2012.

[51] K.-S. Kim, D. Demberelnyamba, B.-K. Shin, S.-H. Yeon, S. Choi, J.-H. Cha, H. Lee, C.-S. Lee, et J.-J. Shim, « Surface tension and viscosity of 1-butyl-3-methylimidazolium iodide and 1-butyl-3-methylimidazolium 
tetrafluoroborate, and solubility of lithium bromide+1-butyl-3-methylimidazolium bromide in water », Korean $J$. Chem. Eng., vol. 23, n 1, p. 113-116, janv. 2006.

[52] J. N. Canongia Lopes, M. F. Costa Gomes, P. Husson, A. A. H. Pádua, L. P. N. Rebelo, S. Sarraute, et M. Tariq, « Polarity, Viscosity, and Ionic Conductivity of Liquid Mixtures Containing [C4C1im][Ntf2] and a Molecular Component », J. Phys. Chem. B, vol. 115, nº 19, p. 6088-6099, mai 2011.

[53] Z.-D. Ding, J.-C. Shi, J.-J. Xiao, W.-X. Gu, C.-G. Zheng, et H.-J. Wang, « Catalytic conversion of cellulose to 5-hydroxymethyl furfural using acidic ionic liquids and co-catalyst », Carbohydrate Polymers, vol. 90, n $^{\circ} 2$, p. 792-798, oct. 2012. 